\title{
Independent Factors Contributing to Daytime and Nighttime Asthmatic Cough Refractory to Inhaled Corticosteroids
}

\author{
Kanemitsu $Y^{1,2}$, Matsumoto $H^{1}$, Oguma $T^{1}$, Nagasaki $T^{1}$, Ito $I^{1}$, Izuhara $Y^{1}$, Tajiri $T^{1}$, I wata $T^{1}$, Mishima $M^{1}$, \\ Niimi $A^{2}$ \\ 'Department of Respiratory Medicine, Graduate School of Medicine, Kyoto University, Kyoto, Japan \\ ${ }^{2}$ Department of Respiratory Medicine, Allergy and Clinical Immunology, Graduate School of Medical Sciences, Nagoya City University, Aichi, \\ Japan
}

J Investig Allergol Clin Immunol 2019; Vol. 29(1): 30-39

doi: 10.18176/jiaci.0281

\begin{abstract}
Background: Cough is a common feature of asthma, which is often resistant to inhaled corticosteroids (ICSs). The pathophysiology of this refractoriness may differ between daytime and nighttime asthmatic cough. We sought to identify factors contributing to ICS-refractory daytime and nighttime asthmatic cough.

Methods: Sixty-seven patients with asthma presenting solely or predominantly with chronic cough were prospectively enrolled from April 2012 to December 2014. At baseline and 12 weeks after ICS treatment, the capsaicin cough threshold (C2, C5) and methacholine airway sensitivity and reactivity were examined. A visual analog scale (VAS) and numeric scores were used to evaluate daytime and nighttime cough symptoms separately. The Japanese version of the Leicester Cough Questionnaire was also completed. When either the VAS or numeric scores showed an improvement of $\geq 50 \%$ or $\geq 2$ points, patients were considered responders to ICS treatment.

Results: Fifty-five patients were eligible for evaluation. Subjective cough indices improved significantly at 12 weeks after ICS treatment $(P<.001)$. Multivariate analysis revealed that lower $C 2$ significantly contributed to residual daytime cough $(P=.04)$. Meanwhile, methacholine hyperreactivity and lower lgE levels were predictors of the nighttime residual cough ( $P=.002$ and $P=.03$, respectively).

Conclusions: Heightened cough reflex sensitivity is an independent factor of daytime asthmatic cough that is refractory to ICSs. In contrast, airway hyperreactivity and less atopic status contribute to ICS-refractory nighttime cough.
\end{abstract}

Key words: Asthmatic cough. Cough sensitivity. Airway reactivity. IgE. Inhaled corticosteroids

\section{Resumen}

Introducción: La tos es una característica común del asma, que a menudo es resistente a los corticosteroides inhalados (ICS). La fisiopatología involucrada en dicha refractariedad al tratamiento esteroideo puede ser diferente entre la tos asmática diurna y nocturna. El objetivo del estudio es intentar identificar los factores que contribuyen a esta insensibilidad al tratamiento en la tos asmática diurna y nocturna. Métodos: Sesenta y siete pacientes, con asma solo o con tos crónica, se inscribieron prospectivamente desde abril de 2012 a diciembre de 2014. Al inicio del estudio y 12 semanas después del tratamiento con ICS, se examinaron el umbral de tos frente a capsaicina (C2, C5) y la sensibilidad y reactividad de las vías respiratorias a la metacolina. Se usaron escalas analógicas visuales (VAS) y puntajes numéricos para evaluar los síntomas de tos diurna y nocturna de forma separada. La versión japonesa del Leicester Cough Questionnaire también se completó. Cuando las VAS o los puntajes numéricos mostraron una mejoría de $\geq 50 \% 0 \geq 2$ puntos, los pacientes se consideraron respondedores al tratamiento con ICS.

Resultados: Cincuenta y cinco pacientes completaron adecuadamente toda la evaluación. Los índices subjetivos de tos mejoraron significativamente a las 12 semanas después del tratamiento con ICS ( $p<0,001)$. El análisis multivariante reveló que una C2 más baja contribuía significativamente a la tos diurna residual $(p=0,04)$. Por otra parte, la hiperreactividad a la metacolina y los niveles más bajos de IgE fueron predictores de la tos residual nocturna ( $p=0,002$ y $p=0,03$, respectivamente).

Conclusiones: La sensibilidad aumentada a la tos es un factor independiente de la tos asmática diurna refractaria a los corticoides. Por el contrario, la hiperreactividad de las vías respiratorias y la ausencia de atopia contribuyen a la tos nocturna refractaria a los ICS.

Palabras clave: Tos asmática. Sensibilidad a la tos. Reactividad de las vías respiratorias. IgE. Corticosteroides inhalados. 


\section{Introduction}

Cough is the most common symptom for which patients seek medical care worldwide. Many patients with chronic cough lasting for 8 weeks or longer are referred to cough specialists. According to an epidemiological study in the United Kingdom, $12 \%$ of the general population complained of cough once a week or more often [1]. Classical asthma and cough-variant asthma are major causes of chronic cough lasting 8 weeks or longer, together with rhinosinusitis and gastroesophageal reflux disease (GERD) [2]. Asthmatic cough is generally alleviated by inhaled corticosteroids (ICSs) [3]. However, a subset of patients are refractory to this mainstay treatment, and cough is associated with poor asthma control in this group, independently of airway obstruction [4].

As was clearly demonstrated by surveys conducted in Europe [5] and Canada [6], nocturnal cough is a common feature of asthma. Meanwhile, asthmatic cough may persist even when other symptoms such as wheezing and dyspnea are stabilized, and this may occur more frequently in the daytime than at nighttime [7]. Indeed, in patients with stable asthma, the objective cough count is predominantly higher in the daytime than at nighttime [7,8]. Marsden et al [8] showed a significant correlation between the frequency of daytime cough and cough reflex hypersensitivity to inhaled citric acid in patients with asthma. However, little is known about the pathophysiology of ICS-refractory daytime and nighttime asthmatic cough.

We hypothesised that different or independent factors are involved in the pathophysiology of ICS-refractory daytime and nighttime asthmatic cough. We conducted this study to identify these factors using subjective cough measures, such as a visual analog scale (VAS), numeric cough scores, and the Japanese version of the Leicester Cough Questionnaire (J-LCQ) before and after treatment with ICSs, with or without long-acting $\beta 2$-agonists (LABAs).

\section{Methods}

\section{Patients}

We prospectively recruited consecutive patients with asthmatic cough ( $\geq 8$ weeks) who first visited our asthma and chronic cough clinic of Kyoto University between April 2012 and September 2014. Patients were eligible for this study if they had not received ICSs or leukotriene receptor antagonists for $\geq 4$ weeks before their first visit. All patients were treated with ICSs at $500 \mu \mathrm{g}$ or higher (fluticasone propionate equivalent) for 12 weeks after the initial diagnosis. The use of LABAs in combination with ICSs as an initial therapy is consistent with the latest version of the national guidelines for the management of cough of the Japanese Respiratory Society (in Japanese, unpublished in English) in the following cases: (1) frequent coughing every day; and (2) daily life and sleeping disturbed by cough once a week or more. We refrained from using leukotriene receptor antagonists and histamine $\mathrm{H}_{1}$ receptor antagonists, as these may attenuate cough by improving cough sensitivity to inhaled capsaicin $[9,10]$. The use of proton pump inhibitors (PPIs) for esophageal symptoms of GERD was permitted only if patients has received them for $\geq 4$ weeks before their first visit, while their use for cough was not permitted. Current smokers, ex-smokers of $>10$ pack-years or those who had quit smoking in the past 6 months, and patients with other pulmonary diseases were excluded.

According to the original version of the Japanese Respiratory Society guidelines for management of cough [11], cough-predominant asthma and cough-variant asthma were defined as follows. The clinical features of cough-variant asthma included chronic cough without wheezing or dyspnea. Patients had almost normal pulmonary function but increased airway responsiveness. In the diagnosis of cough-predominant asthma, cough is the commonest symptom, although mild wheezing is also present. The only difference between cough-predominant asthma and cough-variant asthma is the presence or absence of wheezing. Cough was improved by the inhalation of short-acting $\beta_{2}$-agonists, which is the most specific characteristic finding of cough-predominant asthma and cough-variant asthma [12]. As cough-predominant asthma and cough-variant asthma share clinical manifestations and pathophysiology and their treatments are similar, both are considered asthmatic cough.

This study was approved by the ethics committee of Kyoto University and was registered in the UMIN Clinical Trials Registry (Registry ID UMIN 000007495). Written informed consent was obtained from all participants.

\section{Measurements of Functional and Inflammatory Markers}

All participants underwent a meticulous work-up between 09:00 and 13:00, including blood tests, measurement of fractional nitric oxide (FeNO), impulse oscillometry, spirometry, airway hyperresponsiveness (AHR) to inhaled methacholine, and cough sensitivity to inhaled capsaicin before and after 12 weeks of ICS treatment. Detailed methods for obtaining each measurement have been described elsewhere [9,13-15].

FeNO was measured at an expiratory flow rate of $50 \mathrm{~mL} / \mathrm{s}$ using a chemiluminescence analyzer (NOA 280, Sievers) [13]. Respiratory impedance (resistance at $5 \mathrm{~Hz}$ [R5] and $20 \mathrm{~Hz}$ [R20] and reactance at $5 \mathrm{~Hz}$ [X5]) was determined using a Jaeger MasterScreen impulse oscillometry system (MasterScreen IOS) [14]. Spirometry was performed using a ChestGraph HI-801 spirometer (Chest M.I. Inc). AHR and cough sensitivity were measured using an Astograph device (Chest M.I. Inc). AHR was measured by continuous inhalation of 10 doubling concentrations of methacholine $[15,16]$ (49 to $25000 \mu \mathrm{g} / \mathrm{mL}$ ) for 1 minute for each concentration, following physiological saline inhalation to determine baseline respiratory resistance (Rrs). The total cumulative dose of methacholine after inhaling the highest concentration was 50 units. Patients inhaled methacholine until maximum methacholine concentrations or Rrs reached values 2-fold greater than baseline values, followed by inhalation of salbutamol for 2 minutes. Dmin, the cumulative dose of inhaled methacholine at the inflection point at which Rrs began to increase, was used as an index for airway sensitivity [15]. Astograph can automatically calculate the reciprocal of Rrs, airway conductance (Grs). The slope of the methacholine-Grs dose-response curve (SGrs) is considered an index for airway 
reactivity [16]. Higher values indicate heightened airway reactivity. AHR was considered positive if Dmin was $\leq 12.5$ units [15]. Cough sensitivity was measured by inhalation of 10 doubling concentrations of capsaicin $(0.61$ to $312.5 \mu \mathrm{M})$ for 15 seconds for each concentration at 1-minute intervals, following physiological saline inhalation for 1 minute [9]. The concentrations required to induce at least 2 coughs $(\mathrm{C} 2)$ or 5 coughs (C5) were determined as cough thresholds [9]. The cough sensitivity test was conducted at least 15 minutes after the end of the AHR test.

Serum total and 7 antigen-specific IgE levels (house dust mite, cat and dog dander, Japanese cedar, mixed grass pollens [orchard grass, sweet vernal grass, bermuda grass, timothy, reeds], mixed weed pollens [ragweed, mugwort, goldenrod, dandelion, oxeye daisy), and mixed molds [Penicillium,
Cladosporium, Aspergillus, Candida, Alternaria]) (ImmunoCAP for total IgE and ImmunoCAP for specific IgE, Phadia K.K.) were analyzed at enrolment to determine atopic status. Patients were considered atopic when 1 or more specific IgE antibodies were positive at $\geq 0.35 \mathrm{IU} / \mathrm{mL}$ [17]. The number of sensitized aeroallergens was counted.

\section{Subjective Measures of Cough}

Three subjective cough measures were reported by all participants, namely, cough frequency, cough severity, and cough-specific quality of life.

Numeric cough scores ranging from 0 to 5 reflected cough frequency and severity for both the daytime and nighttime (ie, 0 , no cough during the day or night; 5 , cannot perform usual daytime activities or sleep at all because of severe symptoms) [7].

Table 1. Patient Characteristics

\begin{tabular}{|c|c|c|c|}
\hline & Baseline $(n=55)$ & Final evaluation $(=55)$ & $P$ Value \\
\hline Male/Female & $23 / 32$ & - & - \\
\hline Age & $53.0(16.5)$ & - & - \\
\hline Smoking history, never/ex-smoker & $44 / 11$ & - & - \\
\hline Duration of cough, months & $5(2-240)$ & - & - \\
\hline ICS dose, $\mu \mathrm{g}$ & - & $592(188)$ & - \\
\hline Use of LABA, No. (\%) & - & $31(56)$ & - \\
\hline Comorbid GERD, No. (\%) & $8(14)$ & & \\
\hline Comorbid allergic rhinitis, No. (\%) & $15(27)$ & & \\
\hline Receiving proton pump inhibitors, No. (\%) & $8(14)$ & - & - \\
\hline Receiving nasal corticosteroids, No. (\%) & $2(4)$ & & \\
\hline Serum $\operatorname{IgE}, \mathrm{U} / \mathrm{mL}^{\mathrm{a}}$ & $68(0-5490)$ & - & - \\
\hline Atopic predisposition, No. (\%) & $41(75)$ & - & - \\
\hline Number of sensitized allergens, No. & $2.5(2.5)$ & & \\
\hline $\mathrm{FEV}_{1}, \mathrm{~mL}$ & $2711(985)$ & $2733(879)$ & .64 \\
\hline $\mathrm{FEV}_{1}, \%$ predicted & $106.2(17.0)$ & $107.9(14.3)$ & .35 \\
\hline FeNO, parts per billion & $39.5(44.8)$ & $25.5(12.7)$ & .01 \\
\hline $\mathrm{R} 5, \mathrm{kPa} / \mathrm{L} / \mathrm{s}$ & $0.35(0.13)$ & $0.32(0.11)$ & .04 \\
\hline $\mathrm{R} 20, \mathrm{kPa} / \mathrm{L} / \mathrm{s}$ & $0.31(0.11)$ & $0.28(0.09)$ & .07 \\
\hline $\mathrm{R} 5-\mathrm{R} 20, \mathrm{kPa} / \mathrm{L} / \mathrm{s}$ & $0.05(0.09)$ & $0.04(0.04)$ & .74 \\
\hline $\mathrm{X} 5, \mathrm{kPa} / \mathrm{L}$ & $-0.12(0.06)$ & $-0.11(0.05)$ & .45 \\
\hline $\begin{array}{l}\text { Airway hyperresponsiveness to inhaled met } \\
\text { Dmin, units } \\
\text { SGrs, } \mathrm{L} / \mathrm{sec}^{\mathrm{a}} \mathrm{cmH}_{2} \mathrm{O} / \mathrm{min}^{\mathrm{a}} \\
\text { The presence of } \mathrm{AHR}, \mathrm{n}(\%)\end{array}$ & $\begin{array}{l}1.9(0.001-11.2) \\
0.14(0.009-9.3) \\
\quad 55(100)\end{array}$ & $\begin{array}{c}3.3(0.001-50) \\
0.09(0-16.3) \\
39(71)\end{array}$ & $\begin{array}{l}.06 \\
.0001 \\
.0001\end{array}$ \\
\hline $\begin{array}{l}\text { Cough sensitivity to inhaled capsaicin } \\
\qquad \begin{array}{l}\mathrm{C} 2, \mu \mathrm{M}^{\mathrm{a}} \\
\mathrm{C} 5, \mu \mathrm{M}^{\mathrm{a}}\end{array}\end{array}$ & $\begin{array}{c}9.77(0.61-78.1) \\
19.5(0.61-312.5)\end{array}$ & $\begin{array}{l}9.77(0.61-78.1) \\
19.5(0.61-78.1)\end{array}$ & $\begin{array}{l}.26 \\
.24\end{array}$ \\
\hline
\end{tabular}

Abbreviations: AHR, airway hyperresponsiveness; C2, the concentrations of capsaicin required to induce at least 2 coughs; $C 5$, the concentrations of capsaicin required to induce at least 5 coughs; Dmin, the cumulative dose of inhaled methacholine at the inflection point at which baseline respiratory resistance began to increase; FeNO, fractional nitric oxide; GERD, gastroesophageal reflux disease; ICS, inhaled corticosteroid; LABA, long-acting $\beta_{2^{-}}$ agonist; R5, respiratory resistance at $5 \mathrm{~Hz}$; R20, respiratory resistance at $20 \mathrm{~Hz}$; SGrs, slope of methacholine-airway conductance dose-response curve; $X 5$, respiratory reactance at $5 \mathrm{~Hz}$.

aLog-transformed data were used for comparison before and after ICS treatment. 
A daytime and nighttime cough VAS was also administered every day. The cough VAS is a $100-\mathrm{mm}$ linear scale, on which cough severity is assessed ranging from $0 \mathrm{~mm}$ to $100 \mathrm{~mm}$, with $0 \mathrm{~mm}$ being no cough and $100 \mathrm{~mm}$ being the worst cough imaginable $[8,17,18]$.

Daytime was defined as 06:00 to 22:00, according to the environmental quality standards for noise from the Basic Environment Law in Japan (https://www.env.go.jp/en/air/ noise/noise.html). The mean daily numeric scores and VAS for the 7 days immediately before the commencement of ICS and the final evaluation at 12 weeks were calculated in the daytime and at nighttime. When either the cough VAS or numeric scores showed an improvement of $\geq 50 \%$ or $\geq 2$ points, patients were arbitrarily considered responders to ICS treatment.

Cough-specific quality of life was evaluated using the J-LCQ $[17,19]$, which consists of 19 questions with a 7-point Likert scale covering 3 subdomains (physical, social, and psychological). The total scores range from 3 to 21 . High scores indicate better quality of life [17,19-21]. J-LCQ was translated from the original version [19], and its validity and reliability were confirmed in a previous study [17].

\section{Statistical Analysis}

In order to determine cough frequency and severity by subjective measures, the sample size was set according to a previous study on the correlation between subjective and objective cough measures [8]. By aiming to test approximately 60 patients, subjective cough measures can be considered reliable for the evaluation of the severity and frequency of cough with a power of 0.8 [8].
Data obtained from patients were analyzed using JMP 9.0 (SAS Institute Japan). Data were presented as mean (SD) or median (range) as appropriate. Gender was treated as a dichotomous variable. Nonnormally distributed data were log-transformed. Paired and unpaired $t$ tests were performed to compare data. Multivariate regression analysis was applied to determine factors contributing to ICS-refractory daytime and nighttime asthmatic cough. Variables with a $P$ value $<.10$ in the univariate analysis for pretreatment indices and changes in the indices with ICSs were included in the multivariate analysis, where variables with a $P$ value $\leq .05$ were considered statistically significant.

\section{Results}

\section{Patient Characteristics}

A total of 67 patients with asthmatic cough ( 29 with coughpredominant asthma and 38 with cough-variant asthma) were enrolled. Eight of the 67 patients were lost during the 12-week follow-up, and 4 were also given PPIs, as they were considered to have comorbid GERD potentially associated with cough. Thus, 55 patients were suitable for evaluation (Table 1). Of these, 31 patients $(56 \%)$ received a $\mathrm{LABA}$ in combination with their ICS (ICS/LABA) during the 12-week follow-up. Thirteen patients had a smoking history with an average of 3.8 (3.6) pack-years. Fifteen patients were diagnosed with allergic rhinitis prior to the first visit to our hospital, and 2 of these patients had been treated with nasal corticosteroids for more than 8 weeks. At enrolment, 8 patients had already been
A

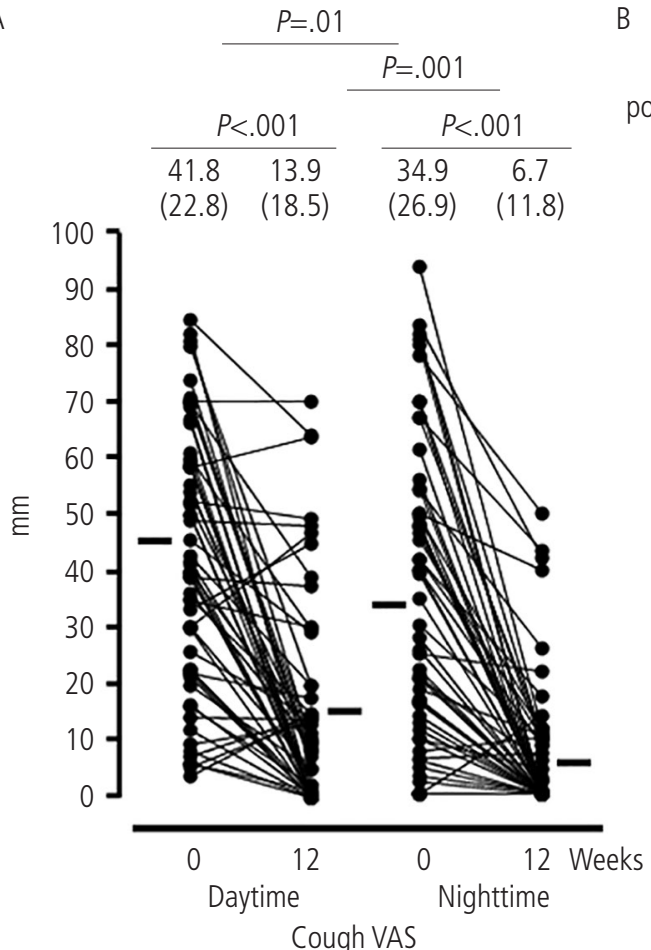

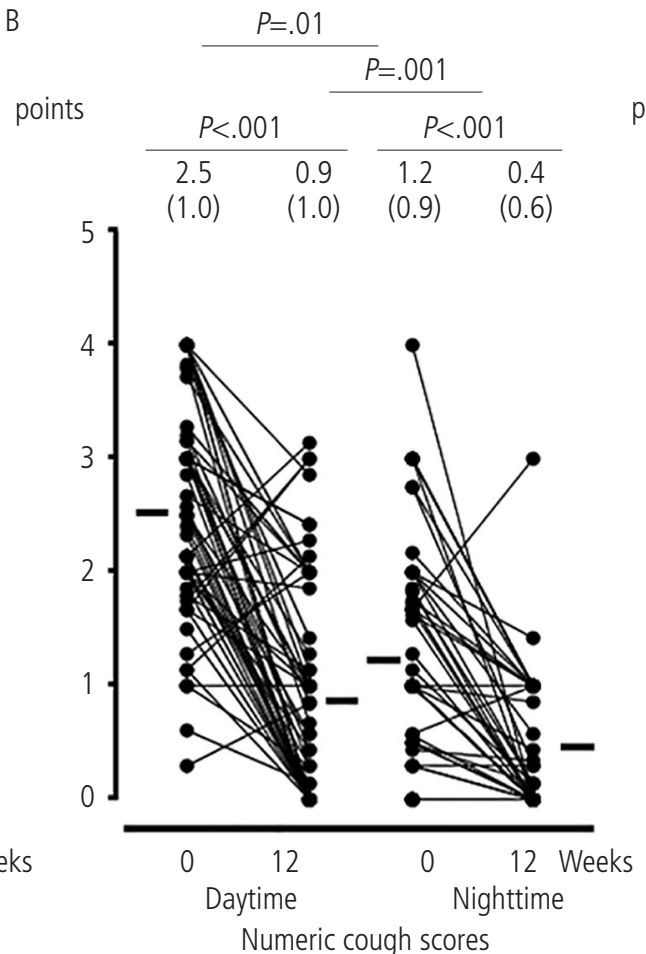

C

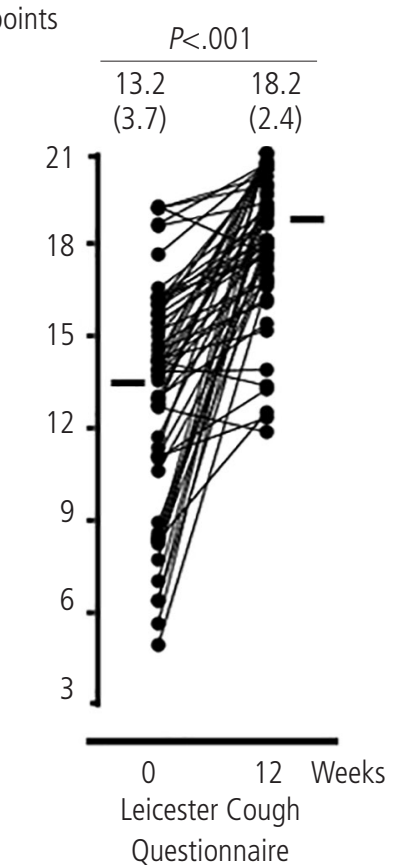

Figure 1. Impact of ICS treatment on subjective cough measures. A, Cough visual analog scales. B, Numeric scores. C, Leicester Cough Questionnaire. 
taking PPIs for esophageal symptoms of GERD, but not for cough. These patients continued this treatment during the follow-up period.

\section{Impact of ICS on Cough Severity and Clinical Indices}

The impact of ICS on subjective cough measures is presented in Figure 1. At enrolment, 7 patients had no nighttime cough. Of these, 6 remained without nighttime cough during follow-up. Cough was more frequent and severe in the daytime than at nighttime both before and after ICS treatment. Cough severity and frequency and coughspecific quality of life were significantly improved with ICS treatment. With respect to the response to ICSs, numeric scores improved significantly for daytime cough compared with nighttime cough ( $P=.001$, Figure 2$)$. On the other hand, the improvement in the VAS was similar between daytime and nighttime cough (Figure 2).

We also evaluated the impact of ICSs on subjective measures of cough stratified according to gender, as females generally have a higher prevalence of asthma and chronic cough than males. When patients were stratified according to gender, there was no difference between males and females in subjective cough indices before initiation of ICSs. All subjective cough measures after ICS treatment except for numeric nighttime cough scores were significantly more marked in females than in males (Figure 3), whereas changes in subjective cough measures with ICS treatment according to gender were not significant (data not shown).

FeNO levels, airway reactivity, and R5 declined significantly with ICS treatment, although spirometry and cough sensitivity remained unchanged (Table 1).

\section{Factors Independently Associated With Daytime and ICS-Refractory Nighttime Asthmatic Cough}

In order to determine factors contributing to ICS-refractory daytime and nighttime asthmatic cough, patients were stratified according to response to ICS treatment. Among the 55 patients, $16(29 \%)$ and $8(15 \%)$ showed a poor response for daytime and nighttime cough, respectively, at 12 weeks after treatment. Of these, 6 complained of ICS-refractory daytime and nighttime cough.

Next, clinical factors associated with ICS-refractory daytime and nighttime cough were investigated. Lower levels of $\mathrm{C} 2$ before ICS treatment and female gender were marginally but not significantly associated with daytime cough $(.05<P<.10)$ (Table 2). Meanwhile, the use of LABAs, lower serum total IgE levels, and lower number of sensitized aeroallergens were significantly related to refractory nighttime cough after ICS treatment (Table 3). Female gender and AHR evaluated by SGrs were marginally associated with refractory nighttime cough. Comorbidities such as GERD and AR were not associated with daytime or nighttime cough (Tables 2 and 3). Similarly, for changes in each index with ICS treatment, no associations were observed with either daytime or nighttime cough (data not shown). Multivariate analysis of factors with $P<.10$ in the univariate analysis revealed that cough hypersensitivity as indicated by lower levels of C2 before ICS treatment only contributed to residual daytime cough after ICS treatment (Table 2). Female gender tended to be associated with ICS-refractory daytime cough. Meanwhile, airway hyperreactivity and lower serum total IgE levels at enrolment were predictors of residual nighttime cough (Table 3). Receiver operating characteristic analyses performed
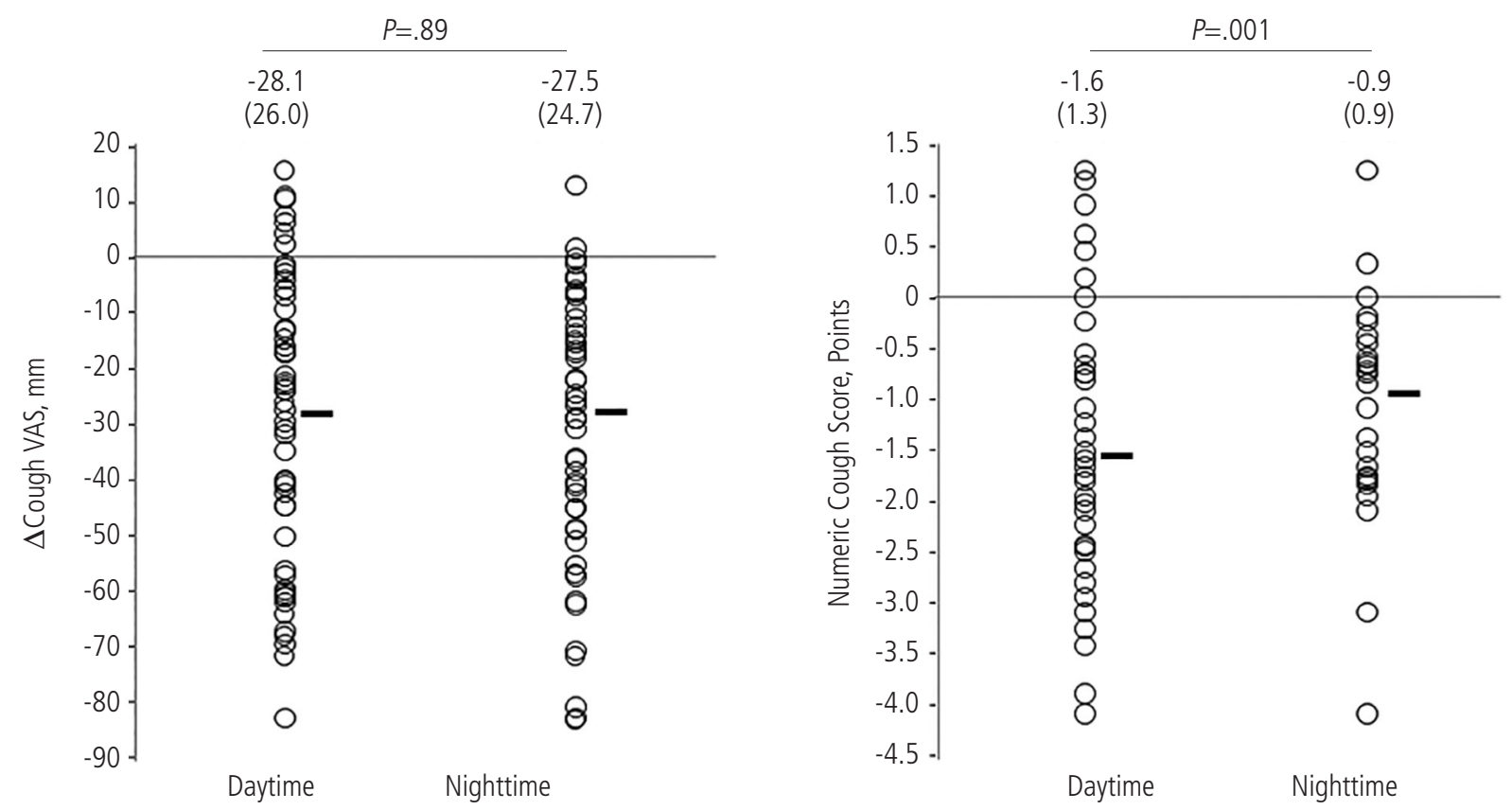

Figure 2. Response to ICS treatment between daytime and nighttime cough frequency and severity. Changes in visual analog scales (A) and numeric scores (B) after treatment with ICS are compared between daytime and nighttime. 
A

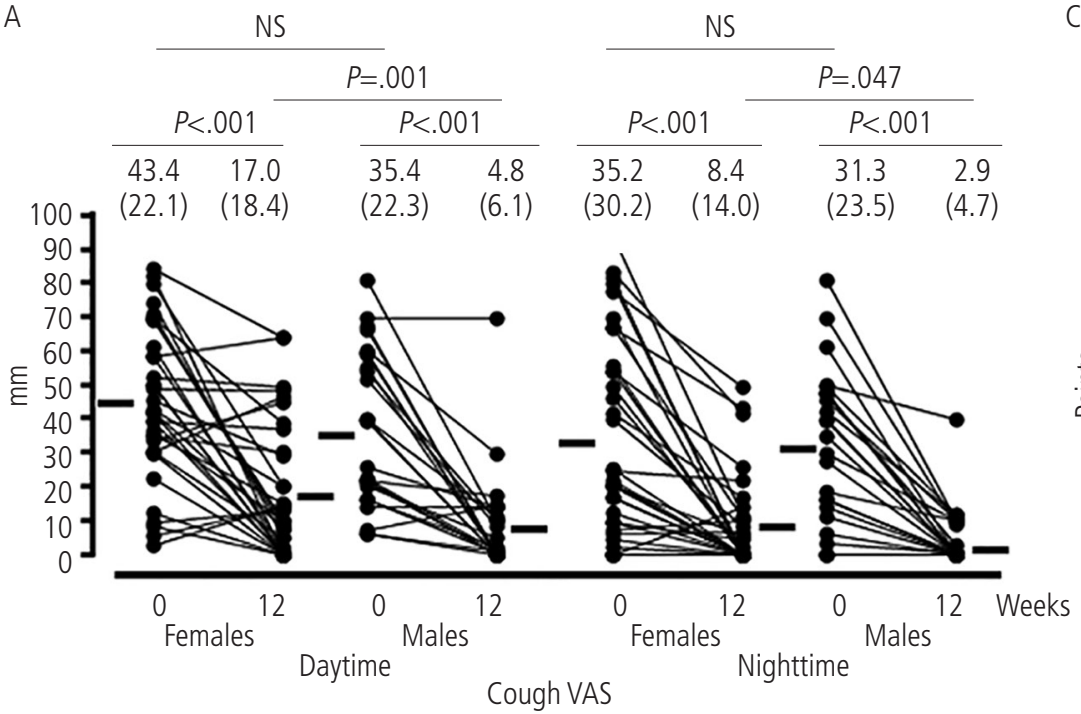

$c$

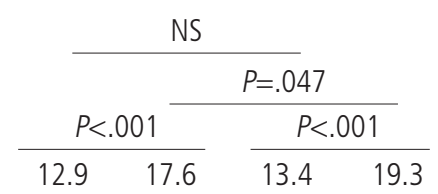

$(3.5) \quad(2.6) \quad(4.2) \quad(1.5)$

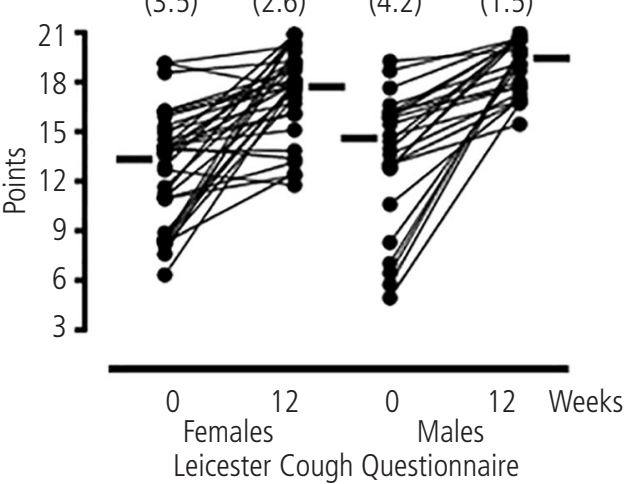

B

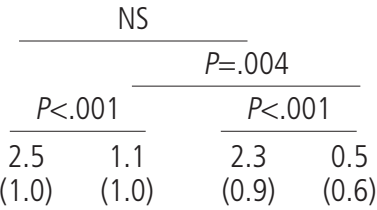

NS

\begin{tabular}{ccccc} 
& & \multicolumn{3}{c}{$P=.004$} \\
\cline { 5 - 6 } \multicolumn{2}{c}{$P<.001$} & & \multicolumn{2}{c}{$P<.001$} \\
\cline { 5 - 6 } 2.5 & 1.1 & & 2.3 & 0.5 \\
$(1.0)$ & $(1.0)$ & & $(0.9)$ & $(0.6)$
\end{tabular}

\begin{tabular}{|c|c|c|c|}
\hline \multirow{2}{*}{\multicolumn{2}{|c|}{$P<.001$}} & \multicolumn{2}{|c|}{ NS } \\
\hline & & \multicolumn{2}{|c|}{$P<.001$} \\
\hline $\begin{array}{c}1.4 \\
(1.0)\end{array}$ & $\begin{array}{c}0.4 \\
(0.7)\end{array}$ & $\begin{array}{c}0.9 \\
(0.7)\end{array}$ & $\begin{array}{r}0.2 \\
(0.4\end{array}$ \\
\hline
\end{tabular}

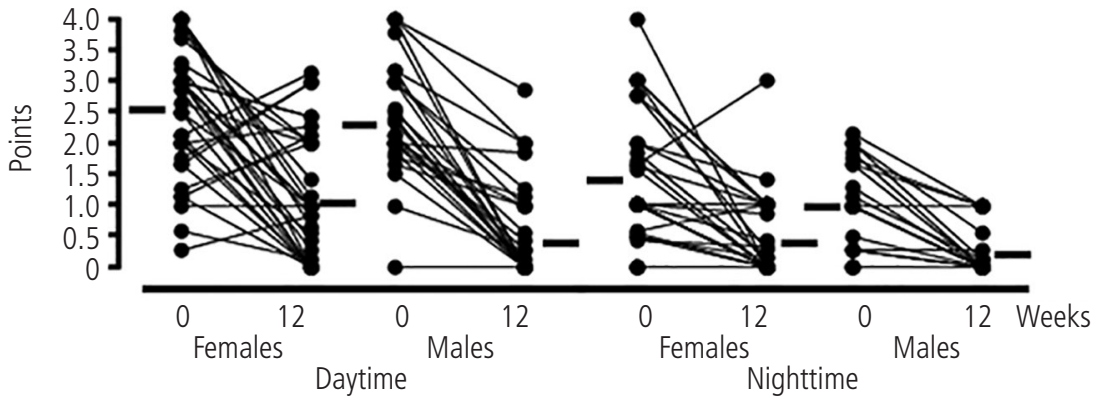

Numeric Cough Score

Figure 3. Gender differences in subjective cough measures between daytime and nighttime. Visual analog scales (A) and numeric scores (B) of daytime and nighttime cough, respectively. Gender difference in cough-specific quality of life (C) is also shown.

using significant indices in the multivariate analysis revealed that serum $\operatorname{IgE}$ of $<50 \mathrm{IU} / \mathrm{mL}$ was a significant predictor of refractoriness to ICS for the nighttime cough, with a high AUC of $0.84(P=.001$, sensitivity $0.875,1$-specificity 0.298 , Figure $4 \mathrm{~A}$ ). Indeed, patients with a good response to nighttime cough had higher serum IgE levels than those with residual nighttime cough ( $284 \mathrm{IU} / \mathrm{mL}$ vs $27 \mathrm{IU} / \mathrm{mL}, P=.005$, Figure 4B). However, the values of $\mathrm{C} 2$ and SGrs were not significant for the detection of refractoriness to ICS for daytime or nighttime cough (data not shown).

\section{Discussion}

To date, ICSs have been the mainstay treatment for asthma symptoms, including cough. In the present study, we confirmed that subjective asthmatic cough occurred more frequently and severely in the daytime than at nighttime both before and after
ICS treatment. ICSs significantly improved numeric scores for daytime cough as compared with those of nighttime cough, while the response of cough to ICSs according to the VAS score was similar for both daytime and nighttime cough. Cough reflex hypersensitivity contributed to residual daytime cough after ICS treatment; AHR and lower serum total IgE levels were predictors of refractory nighttime cough. Thus, independent factors contribute to the refractoriness of daytime and nighttime asthmatic cough to ICS treatment.

Although asthmatic cough is alleviated by ICSs irrespective of the time of day, cough reflex hypersensitivity - as indicated by lower C2 before ICS treatment-was significantly associated with daytime cough that was refractory to ICSs. In studies of the difference in frequency between daytime and nighttime cough using objective cough measures, asthmatic cough was more frequent in the daytime than at nighttime, when patients were stable $[7,8]$. As for the association between gender and cough frequency in patients with chronic cough, 
Table 2. Pretreatment Factors Related to ICS-Refractory Daytime Asthmatic Cough

\begin{tabular}{|c|c|c|c|c|c|c|}
\hline & \multicolumn{3}{|c|}{ Univariate } & \multicolumn{3}{|c|}{ Multivariate } \\
\hline & OR & $95 \% \mathrm{CI}$ & $P$ Value & OR & $95 \% \mathrm{CI}$ & $P$ Value $^{\mathrm{a}}$ \\
\hline Sex, female & 2.85 & $0.83-11.6$ & .098 & 3.53 & $0.96-15.7$ & .06 \\
\hline Diagnosis, cough-variant asthma & 1.43 & $0.44-4.93$ & .56 & - & - & - \\
\hline Smoking history, ex-smoker & 1.52 & $0.35-6.04$ & .56 & - & - & - \\
\hline Duration of cough, mo & 1.003 & $0.99-1.01$ & .59 & - & - & - \\
\hline Age & 0.999 & $0.96-1.04$ & .96 & - & - & - \\
\hline Use of LABA, presence & 1.43 & $0.44-4.93$ & .56 & - & - & - \\
\hline Comorbid GERD, presence & 2.91 & $0.61-14.2$ & .18 & - & - & - \\
\hline Comorbid allergic rhinitis, presence & 0.52 & $0.11-1.99$ & .35 & - & - & - \\
\hline Log serum IgE, U/mL & 0.80 & $0.28-2.17$ & .67 & - & - & - \\
\hline Atopic predisposition, presence & 0.81 & $0.25-2.49$ & .72 & - & - & - \\
\hline Sensitized allergens, No. & 1.04 & $0.81-1.31$ & .76 & - & - & - \\
\hline $\mathrm{FEV}_{1}, \mathrm{~mL}$ & 0.85 & $0.44-1.54$ & .60 & - & - & - \\
\hline $\mathrm{FEV}_{1}, \%$ predicted & 1.02 & $0.98-1.05$ & .35 & - & - & - \\
\hline Fractional nitric oxide, parts per billion & 0.19 & $0.02-1.37$ & .10 & - & - & - \\
\hline $\mathrm{R} 5, \mathrm{kPa} / \mathrm{L} / \mathrm{s}$ & 4.06 & $0.28-62.3$ & .30 & - & - & - \\
\hline $\mathrm{R} 20, \mathrm{kPa} / \mathrm{L} / \mathrm{s}$ & 2.57 & $0.11-55.9$ & .54 & - & - & - \\
\hline $\mathrm{R} 5-\mathrm{R} 20, \mathrm{kPa} / \mathrm{L} / \mathrm{s}$ & 9.55 & $0.07-7353$ & .40 & - & - & - \\
\hline $\mathrm{X} 5, \mathrm{kPa} / \mathrm{L}$ & 0.53 & $0.02-15.8$ & .71 & - & - & - \\
\hline \multicolumn{7}{|c|}{ Airway hyperresponsiveness to inhaled methacholine } \\
\hline Log Dmin, units & 0.77 & $0.44-4.77$ & .35 & - & - & - \\
\hline Log SGrs, $\mathrm{L} / \mathrm{sec} / \mathrm{cmH}_{2} \mathrm{O} / \mathrm{min}$ & 0.77 & $0.32-1.71$ & .53 & - & - & - \\
\hline \multicolumn{7}{|l|}{ Cough sensitivity to inhaled capsaicin } \\
\hline $\log \mathrm{C} 2, \mu \mathrm{M}$ & 0.39 & $0.14-1.005$ & .051 & 0.36 & $0.01-0.93$ & .04 \\
\hline $\log \mathrm{C} 5, \mu \mathrm{M}$ & 0.53 & $0.20-1.36$ & .19 & - & - & - \\
\hline
\end{tabular}

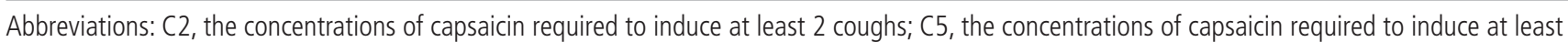
5 coughs; Dmin, the cumulative dose of inhaled methacholine at the inflection point at which baseline respiratory resistance began to increase; FeNO, fractional nitric oxide; GERD, gastroesophageal reflux disease; ICS, inhaled corticosteroid; LABA, long acting $\beta_{2}$-agonists; R5, respiratory resistance at 5 $\mathrm{Hz} ; \mathrm{R} 20$, respiratory resistance at $20 \mathrm{~Hz}$; SGrs, slope of methacholine-airway conductance dose-response curve; X5, respiratory reactance at $5 \mathrm{~Hz}$.

a Other indices with a $P>10$ were not used for the multivariate selections.

including asthma, females coughed more often than males, and heightened cough sensitivity was associated with the increased objective cough count [18]. In healthy adults, the cough threshold is lower during the daytime than during sleep [22]. In a recent study, patients with asthma, especially females and nonatopic patients, showed significantly heightened capsaicin cough reflex sensitivity than healthy individuals [23]. In addition to cough hypersensitivity, female gender tended to be associated with the refractoriness of daytime cough in the current study. Cough reflex hypersensitivity could be involved in the pathophysiology of daytime asthmatic cough persisting after ICS treatment.

Our study also demonstrated that airway hyperreactivity and less allergic status (lower serum IgE levels) were associated with the refractoriness of nighttime cough to ICSs. Because of the nocturnal fall in circulating epinephrine and cortisol, nocturnal worsening of wheezing and airflow limitation are common in patients with asthma, irrespective of their atopic status [24]. Less atopic patients with asthma show a poorer response to ICS treatment. In a study on the association between response to ICSs and decline in lung function, long-term ICS treatment significantly supressed a decline in the $\mathrm{FEV}_{1}$ of patients who had elevated serum total IgE levels ( $\geq 100 \mathrm{kU} / \mathrm{mL})$ [25]. In contrast, this effect of ICSs on pulmonary function was not observed in patients with lower IgE levels [25]. Another study demonstrated that patients with no atopic predisposition or lower serum total IgE levels had a more exaggerated cough response to inhaled capsaicin than atopic patients [23]. In the present study, cough reflex hypersensitivity and less allergic status were not involved together, but separately, in the pathophysiology of daytime and nighttime cough.

Our study is subject to several limitations. First, the number of patients was small (55) and there were no controls. Second, comorbidities such as GERD may have influenced residual daytime and nighttime cough, even if the condition 
Table 3. Pretreatment Factors Related to ICS-Refractory Nighttime Asthmatic Cough

\begin{tabular}{|c|c|c|c|c|c|c|}
\hline & \multicolumn{3}{|c|}{ Univariate } & \multicolumn{3}{|c|}{ Multivariate } \\
\hline & OR & $95 \% \mathrm{CI}$ & $P$ Value & OR & $95 \% \mathrm{CI}$ & $P$ Value $^{\mathrm{a}}$ \\
\hline Sex, females & 6.16 & $0.99-120$ & .052 & 18.8 & $0.20-849$ & .21 \\
\hline Diagnosis, cough variant asthma & 1.35 & $0.30-7.18$ & .70 & - & - & - \\
\hline Smoking history, ex-smoker & 2.93 & $0.52-14.7$ & .21 & - & - & - \\
\hline Duration of cough, months & 1.004 & $0.99-1.01$ & .53 & - & - & - \\
\hline Age & 1.040 & $0.99-1.11$ & .16 & - & - & - \\
\hline Use of LABA, presence & 6.71 & $1.07-130$ & .04 & 7.69 & $0.35-202$ & .26 \\
\hline Comorbid GERD, presence & 2.28 & $0.29-12.9$ & .39 & - & - & - \\
\hline Comorbid allergic rhinitis, presence & 0.34 & $0.02-2.15$ & .28 & - & - & - \\
\hline Log serum $\operatorname{IgE}, \mathrm{U} / \mathrm{mL}$ & 0.07 & $0.007-0.38$ & .001 & 0.009 & $0.00003-0.70$ & .03 \\
\hline Atopic predisposition, presence & 0.27 & $0.05-1.32$ & .11 & - & - & - \\
\hline Sensitized allergens, No. & 0.34 & $0.09-0.70$ & .0006 & 0.72 & $0.12-258$ & .70 \\
\hline $\mathrm{FEV}_{1}, \mathrm{~mL}$ & 0.60 & $0.19-1.31$ & .20 & - & - & - \\
\hline $\mathrm{FEV}_{1}, \%$ predicted & 1.02 & $0.98-1.07$ & .27 & - & - & - \\
\hline Fractional nitric oxide, parts per billion & 0.13 & $0.005-1.81$ & .14 & - & - & - \\
\hline $\mathrm{R} 5, \mathrm{kPa} / \mathrm{L} / \mathrm{s}$ & 3.90 & $0.13-92.1$ & .41 & - & - & - \\
\hline $\mathrm{R} 20, \mathrm{kPa} / \mathrm{L} / \mathrm{s}$ & 3.5 & $0.07-121$ & .51 & - & - & - \\
\hline $\mathrm{R} 5-\mathrm{R} 20, \mathrm{kPa} / \mathrm{L} / \mathrm{s}$ & 3.99 & $0.02-11696$ & 67 & - & - & - \\
\hline $\mathrm{X} 5, \mathrm{kPa} / \mathrm{L}$ & 0.08 & $0.001-3.95$ & .19 & - & - & - \\
\hline \multicolumn{7}{|c|}{ Airway hyperresponsiveness to inhaled methacholine } \\
\hline Log Dmin, units & 0.74 & $0.38-1.49$ & .38 & - & - & - \\
\hline Log SGrs, $\mathrm{L} / \mathrm{sec} / \mathrm{cmH}_{2} \mathrm{O} / \mathrm{min}$ & 2.48 & $0.93-7.12$ & .07 & 32.7 & $2.24-776$ & .002 \\
\hline \multicolumn{7}{|l|}{ Cough sensitivity to inhaled capsaicin } \\
\hline $\log \mathrm{C} 2, \mu \mathrm{M}$ & 0.77 & $0.23-2.59$ & 67 & - & - & - \\
\hline $\log \mathrm{C} 5, \mu \mathrm{M}$ & 0.94 & $0.29-3.30$ & .91 & - & - & - \\
\hline
\end{tabular}

Abbreviations: C2, the concentrations of capsaicin required to induce at least 2 coughs; $C 5$, the concentrations of capsaicin required to induce at least 5 coughs; Dmin, the cumulative dose of inhaled methacholine at the inflection point at which baseline respiratory resistance began to increase; FeNO, fractional nitric oxide; GERD, gastroesophageal reflux disease; ICS, inhaled corticosteroids; LABA, long acting $\beta_{2}$ agonists; R5, respiratory resistance at $5 \mathrm{~Hz}$; R20, respiratory resistance at $20 \mathrm{~Hz}$; SGrs, A slope of methacholine-airway conductance dose-response curve; X5, respiratory reactance at $5 \mathrm{~Hz}$. ${ }^{a}$ Other indices with a $P>.10$ were not used for the multivariate selections.
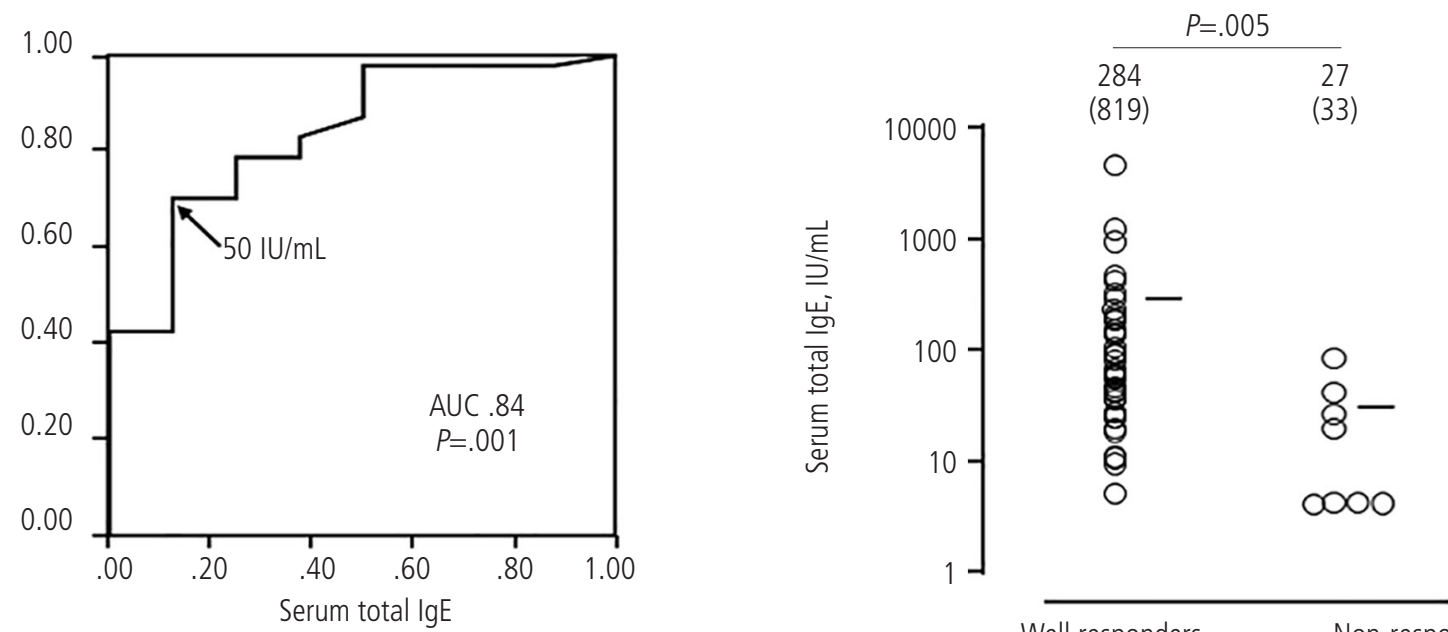

Well responders Non-responders

Figure 4. Total IgE as a predictive biomarker for nighttime cough. A, Receiver operating characteristic curve showing the utility of total IgE as a predictive biomarker for nighttime cough. B, Total IgE levels were compared between good responders and poor responders. 
of such comorbidities was stable. Third, we must take into account seasonal onset or worsening of cough, as well as other conditions such as concomitant rhinitis and atopic predisposition, since these factors may affect the response to ICS. However, when patients were stratified according to the seasons during which they entered the study, the prevalence of rhinitis and atopic predisposition was similar irrespective of the seasons. The seasons and atopic predisposition were also unrelated to response to ICS for either daytime or nighttime cough (data not shown). Therefore, the influence of seasonal bias and allergy on cough could be negligible in this study. In any case, we should have included control groups to exclude the effect of comorbid rhinitis, atopy, and seasonal variation. Fourth, we did not evaluate cough frequency using objective measures. This is because no validated method to record cough sounds is available in Japan. To address this weakness, we determined the number of patients required to assess cough severity and frequency using subjective cough measures according to a previous study [8]. Nonetheless, we cannot exclude the possibility of measurement and recall bias. Fifth, the use of LABAs in $56 \%$ of patients may also have complicated the interpretation of the results. ICS/LABA is often prescribed for initial treatment of asthma in clinical practice. Multivariate analysis revealed no associations between residual daytime and nighttime cough and use of LABAs. Lastly, symptoms of nighttime cough might be underevaluated because nighttime was defined as running from 22:00 to 06:00 of the next day according to the Basic Environment Law in Japan. Meanwhile, previous studies defined day and night as 05:00 to 23:00 and 23:00 to $05: 00$, respectively [7].

In conclusion, cough sensitivity and airway reactivity are independently involved in refractory daytime and nighttime asthmatic cough after ICS treatment. Less atopic status may also contribute to pathophysiology. In order to effectively treat persistent daytime and nighttime cough after ICS treatment, further detailed investigations are needed on the roles of cough reflex hypersensitivity, airway hyperreactivity, and less atopic status.

\section{Funding}

The authors declare that no funding was received for the present study.

\section{Conflicts of Interest}

The authors declare that they have no conflicts of interest.

\section{Previous Presentations}

The summary of this study was presented at the 2016 annual meeting of American Thoracic Society.

\section{References}

1. Ford AC, Forman D, Moayyedi P, Morice AH. Cough in the community: a cross sectional survey and the relationship to gastrointestinal symptoms. Thorax. 2006;61:975-9.

2. Niimi A. Geography and cough aetiology. Pulm Pharmacol Ther. 2007;20:383-7.

3. Morice AH, Millqvist E, Belvisi MG, Bieksiene K, Birring SS, Chung KF, et al. Expert opinion on the cough hypersensitivity syndrome in respiratory medicine. Eur Respir J. 2014;44:113248.

4. Marsden PA, Satia I, Ibrahim B, Woodcock A, Yates L, Donnelly I, et al. Objective Cough Frequency, Airway Inflammation, and Disease Control in Asthma. Chest. 2016;149:1460-6.

5. Janson C, Chinn S, Jarvis D, Burney P. Determinants of cough in young adults participating in the European Community Respiratory Health Survey. Eur Respir J. 2001;18:647-54.

6. Manfreda J, Becklake MR, Sears MR, Chan-Yeung M, Dimich-Ward $H$, Siersted HC, et al. Prevalence of asthma symptoms among adults aged 20-44 years in Canada. CMAJ. 2001;164:995-1001.

7. Hsu JY, Stone RA, Logan-Sinclair RB, Worsdell M, Busst CM, Chung KF. Coughing frequency in patients with persistent cough: assessment using a 24 hour ambulatory recorder. Eur Respir J. 1994;7:1246-53.

8. Marsden PA, Smith JA, Kelsall AA, Owen E, Naylor JR, Webster $D$, et al. A comparison of objective and subjective measures of cough in asthma. J Allergy Clin Immunol. 2008;122:903-7.

9. Takemura $M$, Niimi $A$, Matsumoto $H$, Ueda $T$, Matsuoka $H$, Yamaguchi $M$, et al. Clinical, physiological and antiinflammatory effect of montelukast in patients with cough variant asthma. Respiration. 2012;83:308-15.

10. Fujimura M, Ogawa $H$, Yasui M, Matsuda T. Eosinophilic tracheobronchitis and airway cough hypersensitivity in chronic non-productive cough. Clin Exp Allergy. 2000;30:41-7.

11. Kohno S, Ishida T, Uchida Y, Kishimoto H, Sasaki H, Shioya $T$, et al. The Japanese Respiratory Society guidelines for management of cough. Respirology. 2006;11 Suppl 4:S13586.

12. Irwin RS, French CT, Smyrnios NA, Curley FJ. Interpretation of positive results of a methacholine inhalation challenge and 1 week of inhaled bronchodilator use in diagnosing and treating cough-variant asthma. Arch Intern Med. 1997;157:1981-7.

13. Matsumoto H, Niimi A, Jinnai M, Nakaji H, Takeda T, Oguma T, et al. Association of alveolar nitric oxide levels with pulmonary function and its reversibility in stable asthma. Respiration. 2011;81:311-7.

14. Yamaguchi $M$, Niimi $A$, Ueda T, Takemura M, Matsuoka $H$, Jinnai $M$, et al. Effect of inhaled corticosteroids on small airways in asthma: investigation using impulse oscillometry. Pulm Pharmacol Ther. 2009;22:326-32.

15. Niimi A, Matsumoto H, Takemura M, Ueda T, Chin K, Mishima M. Relationship of airway wall thickness to airway sensitivity and airway reactivity in asthma. Am J Respir Crit Care Med. 2003;168:983-8.

16. Takishima T, Hida W, Sasaki H, Suzuki S, Sasaki T. Directwriting recorder of the dose-response curves of the airway to methacholine. Clinical application. Chest. 1981;80:600-6.

17. Kanemitsu $Y$, Niimi $A$, Matsumoto $H$, Iwata $T$, Ito I, Oguma $T$, et al. Gastroesophageal dysmotility is associated with the impairment of cough-specific quality of life in patients with cough variant asthma. Allergol Int. 2016;65:320-6.

18. Kelsall A, Decalmer S, McGuinness K, Woodcock A, Smith JA. Sex differences and predictors of objective cough frequency in chronic cough. Thorax. 2009;64:393-8.

19. Birring SS, Prudon B, Carr AJ, Singh SJ, Morgan MD, Pavord ID. Development of a symptom specific health status measure for patients with chronic cough: Leicester Cough Questionnaire (LCQ). Thorax. 2003;58:339-43. 
20. Nagata K, Tomii K, Otsuka K, Tachikawa R, Takeshita J, Tanaka $K$, et al. Evaluation of the chronic obstructive pulmonary disease assessment test for measurement of health-related quality of life in patients with interstitial lung disease. Respirology. 2012;17:506-12.

21. Shirai T, Mikamo M, Tsuchiya T, Shishido Y, Akita T, Morita S, et al. Real-world effect of gastroesophageal reflux disease on cough-related quality of life and disease status in asthma and COPD. Allergol Int. 2015;64:79-83.

22. Wang HD, Nakagawa T, Sekizawa K, Kamanaka M, Sasaki H. Cough reflex in the night. Chest. 1998;114:1496-7.

23. Satia I, Tsamandouras N, Holt K, Badri H, Woodhead M, Ogungbenro K, et al. Capsaicin-evoked cough responses in asthmatic patients: Evidence for airway neuronal dysfunction. J Allergy Clin Immunol. 2017;139:771-9.

24. Barnes P, FitzGerald G, Brown M, Dollery C. Nocturnal asthma and changes in circulating epinephrine, histamine, and cortisol. N Engl J Med. 1980;303:263-7.
25. de Marco R, Marcon A, Jarvis $D$, Accordini S, Bugiani $M$, Cazzoletti L, et al. Inhaled steroids are associated with reduced lung function decline in subjects with asthma with elevated total IgE. J Allergy Clin Immunol. 2007;119:611-7.

I Manuscript received December 22, 2017; accepted for publication May 31, 2018.

\section{Akio Niimi}

467-8601 1 Kawasumi, Mizuho-cho, Mizuho-ku, Nagoya, Aichi, Japan

E-mail: a.niimi@med.nagoya-cu.ac.jp 